\title{
Disclaiming EPISTEMic AKRASIA: ARGUMENTS AND COMMENTARIES
}

\author{
VERONICA S. CAMPOS \\ Federal University of Minas Gerais, BRAZIL \\ 182vkai@gmail.com
}

\begin{abstract}
In many ways one's quest for knowledge can go wrong. Since the publication of Amélie Rorty's article "Akratic Believers", in 1983, there has been a great deal of discussion as to one particular form of flaw in reasoning to which we, as less-than-perfect rational entities, are continuously prone to in our epistemic endeavors: "epistemic akrasia" (an analog, within theoretical reason, of the weakness of will that is commonly thought to affect practical reason). The debate that article gave rise became, then, split between authors to whom the idea of epistemic akrasia promotes an interesting diagnosis of some of our intellectual imperfections, and their opponents, those who disclaim the very possibility of the phenomenon. In this paper I'll examine, and present original objections to, four of the main arguments put forward by the latter, showing that none of them have consistently ruled out all the legitimately conceivable forms of the phenomenon.
\end{abstract}

Keywords: epistemic akrasia $\bullet$ akrasia of belief $\bullet$ theoretical irrationality $\bullet$ epistemic irrationality

\section{Preliminary characterization: the akrasia requirements}

Ever since the beginning of the contemporary discussions on the matter, the idea of "epistemic akrasia" has been talked about in terms of an isomorphic of ordinary practical akrasia. Thus, the pivotal question of the debate that has been taking place under such heading - the question of whether or not there is such thing as an epistemic akrasia - has been addressed as the question of whether or not there is something that is, for theoretical reason, what practical akrasia is for practical reason. ${ }^{1}$ Traditionally, practical akrasia is taken to be the behavior displayed by an individual while engaging or being inclined to engage in a course of action that is admittedly at odds with her better judgment as to how she should act, in contexts in which it would be possible for her to not so engage. ${ }^{2}$ Similarly, the idea of epistemic akrasia amounts to the behavior displayed by an individual in acquiring or maintaining epistemic attitudes (such as beliefs) that are admittedly at odds with her better intellectual judgment (i.e., her judgment as to, for example, what stands she should 
take, considering what the situation pushes her based on the information at hand), in contexts where it would have been possible for her to not so behave.

Strictly speaking, for one's practical behavior to be correctly captured by the idea of practical akrasia, she must acknowledge, implicitly or explicitly, that the action she performs or is inclined to perform is at odds with her better practical judgment, i.e., her judgment as to what would be the best thing for her to do. That is, it does not suffice that there be dissonance between what one does or is inclined to do and her better judgment, neither it suffices that there be dissonance between the action in question and her other inclinations - to talk of akrasia is to talk of cases in which one acknowledges the dissonance as such. This is how the notion is treated contemporarily (by authors such as Davidson 1980 pp.22-23), and this is also how it is described classically (by Aristotle in the Nicomachean Ethics, for example). ${ }^{3}$ Call this the "judgment condition" for practical akrasia.

Concomitantly, only cases in which things are such that it would have been possible for the action in question to not be or not have been performed are eligible to be correctly captured by the idea of practical akrasia: if one feels she is about to pass out in the presence of a rabid dog whilst her better practical judgment tells her that the best thing to do is to run, her behavior is not akratic, for passing out, though blatantly (and admittedly) at odds with her better judgment, is not such that she could have done otherwise. Call this the "control condition" for practical akrasia.

This also matters for the sake of delimitation. The first condition, the judgment condition, renders akrasia distinguishable from ordinary mistaking (i.e., the performing of an inappropriate action which is not so acknowledged by the agent whose action it is, or which is only so acknowledged later on); and prevents cases of hypocrisy from being described as akratic (i.e., cases in which one acts contrary to what she seems to deem best, but doesn't). The second one (the control condition), in turn, prevents the behavior exhibited by thermometers, smoke detectors and non-rational entities from being described as akratic. In short, if we are entitled to state, about a particular episode $\alpha$, that $\alpha$ meets these two conditions, we must acknowledge that $\alpha$ is an instance of practical akrasia. At the same time, if we claim, regarding a particular episode $\alpha$, that $\alpha$ is a case of practical akrasia, we are committing ourselves to the claim that $\alpha$ meets both of the conditions, insofar as this is implicit in the very use of the concept. ${ }^{4}$

\section{The disclaimers' characterization of epistemic akrasia}

Some authors deny that an epistemic analog of practical akrasia casted in isomorphic terms (i.e., satisfying the two abovementioned conditions) is possible. ${ }^{5}$ Their argumentative path stems from the following considerations: if it indeed exists, within the 
epistemic domain, a phenomenon that is isomorphic to practical akrasia, for one's epistemic behavior to be correctly described as one of its instances, she must implicitly or explicitly acknowledge that a belief she acquires or holds is at odds with what she thinks it would be the right belief to be acquired or held; and, concomitantly, things must be such that it would have been possible for her to not so behave. That is, there must be epistemic equivalents of the judgment condition as well as of the control condition. Also, due to the presupposition of isomorphism between the practical and the epistemic varieties of the phenomenon, cases involving unconscious beliefs cannot, prima facie, be correctly described as cases of epistemic akrasia, even if their content is as odds with what one thinks she should believe, since the fact that they are unconscious prevents the individual from acknowledging the dissonance. Likewise, variations of cases in which one has a belief inoculated into her doxastic mesh by an evil genius are also precluded from being correctly described as instantiating the phenomenon, as these are emblematic cases of which we are willing to say that one was completely oblivious to the acquisition of the beliefs in question.

In other words, if there is an epistemic phenomenon that is, in a relevant sense, isomorphic to practical akrasia, for one's behavior to be correctly described as instantiating this phenomenon we must be entitled to state that such an individual acknowledges her acquiring or holding of a belief that is at odds with her better epistemic judgment; and that she could have, as well, not acquired or held such a belief. At the same time, if we are willing to state, as to a particular episode $\beta$, that $\beta$ is an episode of epistemic akrasia, we commit ourselves to $\beta$ meeting the two abovementioned isomorphic conditions: the epistemic judgment condition and the epistemic control condition.

The heart of the matter, then, is whether there could be any $\beta$ episode that simultaneously meets the two isomorphic conditions. By rewriting the considerations presented so far in a more technical fashion, we have:

The action involved in a practical akrasia episode is acknowledged by the individual herself as dissenting from her better practical judgment. (ACK)

Things are such that it was possible for the action involved in the practical akrasia episode to not have been performed. (CTRL)

Supposing that

Epistemic akrasia episodes are isomorphic to practical akrasia episodes (ISO),

We thus have

The belief involved in an epistemic akrasia episode is acknowledged by the individual herself as dissenting from her better epistemic judgment. (C1, from ACK and ISO) 
and

Things are such that it was possible for the belief involved in the epistemic akrasia episode to not have been acquired or held. (C2, from CTRL and ISO)

" $C 1$ " is the technical characterization of the epistemic judgment condition, while " $C 2$ " is the technical characterization of the epistemic control condition. To summarize, the fundamental concern of the debate around the possibility of epistemic akrasia is whether there is any interpretation available to ISO which does not render it impossible in principle for $C 1$ or $C 2$ or both to be met; or, in other words, whether $C 1$ and $C 2$ can be simultaneously met without undermining ISO. ${ }^{6}$

As the case has been framed, for $C 1$ to be met, the agent must have a better epistemic judgment, ${ }^{7}$ that is, ISO must be interpreted as entailing that agents have theoretical evaluative judgments, in general, and a specific variety of such judgments, in particular: the judgment all-things-considered as to what one should believe (better epistemic judgment). For C 2 to obtain, in turn, ISO must be interpreted as entailing that agents have some control over belief acquisition, in general, as they have over the undertaking of courses of action, in general. Let us get into these two issues, one at a time.

There is more than one way of understanding the nature of evaluative judgments, of which "better judgments" are specimens. Traditionally, evaluative judgments (such as the judgment that certain course of action is better than another) are thought to have a special character in relation to other types of judgment, such as perceptual judgments (for example, that $A$ is yellow, or that $A$ is more yellow than $B$ ) as well as descriptive judgments (for example, that $A$ is expensive, or that $A$ is more expensive than $B$ ). What evaluative judgments have that other kinds of judgment don't is the property of being action-guiding: of purporting an answer to the practical question "what should I do?", of providing one with a motivation to do something.

As the idea of epistemic akrasia is featured by its disclaimers, the interpretation that must be given to ISO so that $C 1$ is met is one that allows for evaluative judgments that are epistemic isomorphics to practical evaluative judgments - that is, evaluative judgments that have, as their object, not practical attitudes, such as actions, but rather epistemic attitudes, such as beliefs. In particular, the interpretation that must be given to ISO is one that allows for theoretical evaluative judgments that are belief-guiding (that serve as a guide or motivation to belief acquisition); and among those, the special kind of evaluative judgment, the so called "better judgment" - there must be a special kind of theoretical evaluative judgment that specifies something of the sort " $\mathrm{m}$ is what one is supposed to believe under such and such circumstances".

In more technical terms, the interpretation that must be given to ISO so that $C 1$ can be met is one in which ISO implies TEJ: 
There are theoretical, or doxastic, evaluative judgments that play in theoretical reason a role analogous to the one played by practical evaluative judgments in practical reason. (TEJ)

The control we have over belief acquisition too can be conceived in more than one way. We routinely influence our doxastic states indirectly, by selectively exposing ourselves to evidence, by deciding to carry on or deciding to close investigations, etc. Authors such as Owens (2002) and Adler (2002a), however, believe that this would have to be a sort of direct control (literally analogous to the one we have over our actions) for $C 2$ to be met. That is, they take $I S O$ as needing to be interpreted as implying $C B$ :

Beliefs are something over which we have as much control as we have over actions. (CB)

That said, we gain access to the variety of arguments available to an epistemic akrasia disclaimer, which are basically variations of two strategies: denying TEJ and denying $C B$. In what follows I'll present and discuss variants of four arguments that run these two strategies.

\section{Arguments against $\mathrm{C} 1$ charging TEJ}

If practical evaluative judgments are action-guiding by definition, strictly speaking, TEJ sounds quaint. This is because we do not ask ourselves questions such as "what am I supposed to believe?", at least not ordinarily, nor in the same spirit as when we ask the practical question "what am I supposed to do?". This is because beliefs are not the kind of thing that is acquired from, or by, the following up of recommendations. Beliefs seem to be the kind of thing that is "naturally" given out of our accessing of evidence. Say $q$ is evidence for $p$ once $q$, being true, renders $p$ true or increases the probability that $p$ be true - we acquire the belief that $p$ (or a degree $x$ of belief that $p$ ) directly from our appreciation that $q$ is true, no "recommendations" being involved in the process.

When we ask ourselves questions of the form "what am I supposed...?" we're actually seeking recommendations. What evaluative judgments do is to purport recommendations (this being is precisely what makes them the kind of judgment they are). Purporting as well as following recommendations presupposes that we take the very thing that is recommended as something we could either follow or not follow - there are no recommendations on what we take as following by necessity, or invariably, independently of our will. There are no recommendations on, for instance, whether or not we're supposed to see infrared, or agree that every bachelor is unmarried, for these things hold completely independent of our endorsements. If 
practical evaluative judgments provide us with recommendations, and if there are only recommendations on what we can endorse, then the idea that there are theoretical evaluative judgments playing in theoretical reasoning a role similar to the one played by practical evaluative judgments in practical reasoning (TEJ) sounds difficult to understand - there might be a vague similarity between these two roles, but not a real analogy, or isomorphy. And if this is so, then the one thing one's belief would have to be at odds with for $C 1$ to be met simply doesn't exist.

An argument charging TEJ so as to prevent $C 1$ from being met, more or less within the contours just outlined, can come in two "flavors". It can

Deny TEJ simpliciter, i.e., by stating that there are no theoretical or doxastic evaluative judgments (strategy I)

Or it can

Deny TEJ with qualification, by claiming that there are theoretical or doxastic evaluative judgments, but that they do not play in theoretical reason a role analogous to the one played by practical evaluative judgments in practical reason (strategy II)

\subsection{Pettit \& Smith's argument}

A specimen of such an argument has been put forward by Pettit and Smith (1996, p.448):

Imagine that your beliefs run counter to what evidence and fact require. In such a case, your beliefs will not allow those requirements to remain visible because the offending beliefs themselves give you your sense of what is and your sense of what appears to be. You are therefore denied an experience whose content is that you are believing such and such in defiance of the requirements of fact and evidence. This is why, as G. E. Moore observed, you cannot simultaneously think that while you believe that $p$, yet it is not the case that $p$.

It is not quite clear from Pettit and Smith's excerpt which of the two strategies was intended. The passage is interpretable as stating that the reason $C 1$ cannot be met is that beliefs are acquired not by means of a "better epistemic judgment", but rather from our direct apprehension of what facts and evidence require, which is a variation of (I). Or it can be interpreted as stating that the reason $C 1$ cannot be met is that beliefs are acquired on the basis of better epistemic judgments, but that these, in turn, correspond to our direct apprehension of what facts and evidence require, and once this kind of judgment is not belief-guiding, TEJ does not hold, which, in turn, is a variation of (II). Or the excerpt can yet be interpreted as stating that TEJ is false because better practical judgments can be countered while theoretical ones cannot 
(countering a better theoretical judgment requires incurring in a paradoxical state of mind, one that can only be expressed by a Moorean sentence; and is, therefore, an impossible state of mind) which is another variation of (II).

From this last available interpretation the argument is not a very promising one and it has already faced objections from Owens (2002, pp.382-3) - there's no reason to think that countering a better theoretical judgment couldn't come out as a much less "disturbing" and non-paradoxical sentence. Pettit and Smith's case against $C 1$ sounds more promising when spelled out from the other two interpretations. According to the other variation of (II), they are to be taken as stating something along these lines: what I believe is given by what I take as being what I'm supposed to believe, that is, by my better epistemic judgment. And my better epistemic judgment, in turn, is given by my apprehension of facts and evidence. So if I acquire a belief $\mathbf{m}$ that goes against what facts and evidence actually require from me, this will turn out to happen because I've misapprehended facts and the evidence (after all, had I apprehended them correctly, my belief $\mathbf{m}$ and them would not be dissonant, but rather consonant). But if I've misapprehended facts and evidence, and if it is from this misapprehension that I come to acquire $\mathbf{m}$, then I simply cannot realize that $\mathbf{m}$ is at odds with what the facts and evidence actually require from me. From my own point of view, $\mathbf{m}$ is perfectly consonant to what the facts and the evidence require, for I think that what they require simply is what I took them as requiring. Thus, while it is possible for an individual to believe something that is at odds with what the facts and evidence actually require, it is not possible for her to believe something that is at odds with what she herself takes as being what the facts and evidence require. Since beliefs are formed by virtue of our own apprehension of facts and evidence, and of what we take them as requiring (better epistemic judgment), it is impossible for anyone to have a belief admittedly at odds with what she herself takes as what she is supposed to believe.

Within this variant, the argument states that beliefs are formed on the basis of a better epistemic judgment, but that this, in turn, does not play the role of guiding belief formation. That is, better epistemic judgments are not belief-guiding, their role being best described as belief-constraining: they constrain (i.e., they causally determine, rather than recommend, or motivate) belief acquisition, restricting belief content to the realm of what facts and evidence were taken as requiring. Therefore, these judgments are not isomorphic, in the epistemic field, to better practical judgments (TEJ is false).

The problem with this argument is that it depends on this belief-constraining process (the process by means of which one's better epistemic judgments produce beliefs) being infallible in order for the non-isomorphism it stands up for to hold. ${ }^{8}$ If an agent's better epistemic judgment always comes out as the acquisition, by the agent, of the recommended belief, then it in fact seems there's no way the beliefs 
acquired by an agent could be at odds with her better epistemic judgment, for the content of those beliefs will always be tacitly given in accordance with what such a judgment specifies. If, however, one's better epistemic judgment can fail in its task of generating the correspondent belief, an eventual flaw in the process may result in a state of affairs in which the acquisition of a belief whose content is specified by one's better judgment simply does not occur. I'm talking about cases in which one already holds a belief not-m and, at some point, her better epistemic judgment tells (qua constrains) her to acquire $\mathbf{m}$, so that she must acquire $\mathbf{m}$ and let go of not-m in order to preclude the state of dissonance that would otherwise characterize $C 1$. However, it seems that the constraining force exert by this judgment failing (so that $\mathbf{m}$ ends up not being incorporated to one's doxastic mesh, thus leading to not-m not being replaced) is a live possibility. In such a case, one ends up in a situation where she has a belief not-m at the same time as her better epistemic judgment tells her to believe $\mathbf{m}$. If such cases are possible, we should concede to Pettit and Smith that the isomorphism between epistemic and practical better judgments may not be total (if the latter are action-guiding whereas the former are belief-constraining); but yet these two types of judgment are isomorphic in the relevant sense that they may or may not succeed in their respective tasks, which restores TEJ. The question with which Pettit and Smith's argument needs to be confronted, then, is the question of whether cases like the abovementioned one are possible.

The reason we are prone to imagine that such cases are not possible is that we are too used to taking basic perceptual beliefs - such as the belief that the wall on my left is white, for example - as the default specimen of the belief category. Cases like the one we've been discussing (i.e., cases in which one's better epistemic judgment fails to translate into the actual acquisition of belief) are hard to conceive if we think about them as involving perceptual beliefs, despite their being pretty conceivable if we think of them as involving a myriad of other types of beliefs. In fact, if I access the fact that the wall on my left looks white and if I judge all things considered that it looking white under adequate light conditions is a sufficient reason for me to believe that it is white ( $\mathbf{m})$, then even if I have been believing until then that the wall was beige (not-m), it seems that I naturally acquire $\mathbf{m}$ and let go of not-m; and the idea that things could turn out differently sounds pretty counterintuitive. So we are willing to straightforwardly admit that in the case of perceptual beliefs the advent of a better judgment naturally comes out as the acquisition of the corresponding belief. Now take a case involving non-perceptual beliefs, presented by Mele (1986, pp.218-9):

\section{WILMA}

Suppose, e.g., that Wilma judges not only that the evidence that her twelve year old son, Basil, has been experimenting with narcotics is very strong and much stronger than the contrary evidence, but also that her believing that he 
has been doing so is much better supported by nonepistemic considerations than is her not believing this. She thinks that even if the epistemic evidence were significantly weaker it would be best, practically speaking, for her to believe that Basil has been taking drugs, for she fears that in the absence of this belief it would be very easy for her to fail to give him guidance that he may well need. To be sure, Wilma wants it to be false that her beloved Basil has been using drugs and she recognizes that believing that he has been doing so would be very painful for her, but she judges that the pain is outweighed by other practical considerations. Undoubtedly, many more details can be added to the story of Wilma's finally coming, on the basis of epistemic and non-epistemic considerations, to hold the judgment that there is good and sufficient reason for her not believing that Basil is innocent of drug use. However, let us suppose now, for the sake of brevity, that she does come to hold this judgment but that she nevertheless believes that he has not been using drugs.

The Wilma case was entirely settled by Mele on the basis of assumptions ("suppose Wilma judges that..." and "... suppose that she nevertheless believes..."). Notwithstanding, we have the strong intuition (from which the example derives its strength) that cases such as Wilma's are altogether possible and even a commonplace. Wilma ends up with her better judgment pushing her to the belief $\mathbf{m}$ that Basil is experimenting with drugs while preserving (that is, while still holding) the belief not-m that he is not so experimenting - the most natural explanation for what is at stake seems to be that her better judgment is failing to effectively come out (either by constraining, motivating, or by whatever means) as the acquisition of $\mathbf{m}$ and, because it is thus failing, Wilma's final situation is precisely one in which the state of dissonance characteristic of $C 1$ prevails.

Someone could object that if Wilma did not actually acquire the belief $\mathbf{m}$, it is because she did not effectively judge all things considered that she should acquire $\mathbf{m}$ at that time, for, had she so judged, she would have acquired $\mathbf{m}$. This objection sounds a little exotic, once the case, as it is featured by Mele, already specifies that Wilma's judgment that she'd better believe that Basil is experimenting with drugs is her judgment all things considered - it was even formed on the basis of epistemic and non-epistemic considerations, that is, it took into account "all things". ${ }^{9}$ Such an objection strikes out the hypothetical character of the example by suggesting that what Mele supposed was possible is actually not possible, though our ordinary intuitions, it seems, are on Mele's side. This objector could claim that better judgments are of such a nature that one's acquired beliefs express them (and not that they play a role in belief acquisition, either by constraining or by guiding it). So that if Wilma's judgment that it would be better to believe that $\mathbf{m}$ doesn't translate into the actual acquisition of the $\mathbf{m}$ belief, then this simply wasn't her better judgment on the matter but rather an ordinary (all-out) one. ${ }^{10}$ 
This establishes something that actually renders it impossible for one's beliefs to be at odds with one's better epistemic judgment: it establishes a sort of impediment on principle, in that it fixes acquired beliefs as inexorably expressing better judgments and, therefore, as inexorably consonant to them and, if this is right, the Wilma case would have been spuriously casted by Mele. But in this case scenario the objector is disagreeing about the very nature of evaluative judgments - he is taking evaluative judgments, as judgments that play a role (of whatever kind) in belief acquisition to not exist. This is precisely the first interpretation available to the argument against $C 1$ charging TEJ to which we've alluded, the one that denies that evaluative judgments understood as judgments that play a role in belief acquisition (TEJ) exist.

A similar position with respect to practical evaluative judgments was held by moral philosopher R. M. Hare (1952, 1963). Hare advanced a general theory on the nature of evaluative judgments according to which one's better (practical) judgment is revealed by one's actions. To Hare, from the action actually taken by a person it follows that she judged that action to be the most appropriate, all things considered, at the time (and not the other way around). Thus, for him, "it is analytical to say that one always does what she thinks best all things considered" (Hare 1952, p.169). Patently, anyone who defends such a view seems constrained to accept that there is no practical akrasia insofar as CTRL cannot be met (Hare, for instance, argues that what happens in episodes that appear to be of practical akrasia is that the individual gives in to strong emotions).

One could hold, as to the epistemic field, a position analogous to the one held by Hare in the practical-moral field; and this may have been what Pettit and Smith intended, if they are to be interpreted according to (I). The idea that theoretical evaluative judgments play no role within belief acquisition, however, is pretty at odds with the common intuition that they do. We share a vivid intuition that we exercise our critical skills, i.e., that it is on us to analyze and deliberate as to what each situation require from us, epistemically; and that the beliefs we come to hold derive from these analyses and deliberations at least in some of the cases. We, for instance, weight evidence, by comparing what goes for certain statements and what goes against them before we close our minds upon a particular belief; and we even rebuke others when they not do so. This being so in at least some cases ensures that no position analogous to Hare's within the epistemic domain reflects all that there is to the nature of epistemic evaluative judgments.

\subsection{Adler's argument}

Another argument against $C 1$ charging TEJ was presented by Jonathan Adler (2002a, 2002b). Take the following two excerpts, from Adler (2002b, p.69 and 2002a, p.8, respectively): 
Theoretical reasoning is likened to practical reasoning because the former seeks to determine which hypothesis is best supported by the available evidence. The analogy [the alleged analogy between practical and theoretical reasoning] implies that, just as the objective of practical reasoning is to discover which option is best all things considered, the objective of theoretical reasoning is to discover which hypothesis is best supported on the total available evidence. It is this implication that is misleading. For the objective of theoretical or empirical reasoning is determining whether a hypothesis is true, not whether it is best supported.

If evidence is adequate to accept a hypothesis, no (previously) conflicting evidence can retain its (epistemic) force against that hypothesis. So no evidence remains that can motivate belief against the hypothesis justified by one's evidence, as the desires disfavored in an akratic judgment [...] still retain a pull on the agent, and so can motivate him to act against it. So weakness of belief — as believing in opposition to one's evidence — is motivationally unintelligible.

Adler's argument is a variant of (II). He acknowledges that there are theoretical evaluative judgments and that they do play a role within belief acquisition, but he denies the isomorphism between them and the practical variety - not exactly because the kind of role played by each of them in their respective domains is different, but rather because the very structures of theoretical and practical reasonings, according to Adler, differ significantly: they operate according to different norms, or rules, and have different purposes, so that there is no isomorphism between the realms to which each of them pertain.

Adler's core idea is as follows: theoretical reasoning is fundamentally different from practical reasoning in that the alternatives envisioned in the former are mutually exclusive in a way that is different from the way in which alternatives are mutually exclusive when reckoned in the latter. ${ }^{11}$ When two concurrent possibilities of action, A and $\mathbf{A}^{\prime}$, are placed before a subject so that she feels inclined to both but can only undertake one, accessing motivational elements that reinforce her inclination to $\mathbf{A}$ does not weaken her inclination to $\mathbf{A}^{\prime}$, and vice-versa. Thus, if one comes to the conclusion that it would be better all things considered to pursue a career in medicine and settle in a large urban center (A), her inclination to join the hippie movement and go live a nomadic or rural lifestyle $\left(\mathbf{A}^{\prime}\right)$ does not vanish. Even if she does undertake $A$, her inclination to $\mathbf{A}^{\prime}$ remains, being experienced in the form of "a kind of regret" (Adler 2002a, p.6). This is because although A was deemed the best life choice allthings-considered, $\mathbf{A}^{\prime}$ was judged better all-out, that is, with respect to other (partial) parameters - better from the specific point of view of being in touch with nature, for example - and it continues to be so deemed even in the face of the all-thingsconsidered conclusion that what one is supposed to do is A. Thus, in a case in which 
one undertakes $\mathbf{A}^{\prime}$ contrary to her better judgment according to which she is supposed to do A (an archetypal case of practical akrasia) the undertaking of $\mathbf{A}^{\prime}$ can only occur because the motivational elements that inclined her to $\mathbf{A}^{\prime}$ haven't disappeared after the establishment of the better judgment.

The same does not hold for theoretical reasoning, according to Adler (2002b, p.263). When two concurrent claims $\mathbf{P}$ and $\mathbf{P}^{\prime}$ are placed before someone, the set of reasons $\mathbf{f}$ that she deems good and sufficient for $\mathbf{P}$ automatically defeat ${ }^{12}$ the reasons $\mathbf{f}^{\prime}$ in favor of $\mathbf{P}^{\prime}$, since $\mathbf{P}$ and $\mathbf{P}^{\prime}$ cannot be both true at the same time. ${ }^{13}$ Thus, Adler states, when good and sufficient reasons favor certain belief, "the disfavored belief evaporates, since it has been determined to be false" (Adler 2002a, p.6).

This entails that if reasons $\mathbf{f}$ are deemed good and sufficient for (for example) a person to accept $\mathbf{P}$, then this all-out judgment $(\mathbf{f} \therefore \mathbf{P})$ is the ultimate goal of theoretical reasoning, so that there is not - as there is in practical reasoning - an "all-thingsconsidered" judgment from which the "all-out" judgment could dissent. Then, by judging all-out that $\mathbf{f} \therefore \mathbf{P}$, according to Adler, one automatically $i$ ) acquires the belief that $\mathbf{P}$; and $i i$ ) deems any rival hypothesis $\mathbf{P}^{\prime}$ false (insofar as $\mathbf{f}$ defeats $\mathbf{f}^{\prime}$ which would otherwise serve as reason for the acquisition of $\mathbf{P}^{\prime}$ ) and abandons it (Adler 2002a, pp.6-7).

Apart from the question of whether the process (of whatever sort it may be) involved in ( $i$ ) can fail, which was already addressed when we discussed the Wilma case, if Adler is correct that (ii) is a consequence of the all-out judgment that certain reasons are good and sufficient to support a given belief, one can't ever acquire a belief that is admittedly at odds with what she herself takes as being what she is supposed to believe (her better epistemic judgment). That is to say, the situation described by $C 1$ cannot occur, simply because there are no better judgments at stake in theoretical reasoning - the establishment of the all-out judgment that $\mathbf{f}$ are good and sufficient for $\mathbf{P}$ (the all-out judgment $\mathbf{f} \therefore \mathbf{P}$ ) is all that it takes for one to acquire the belief that $\mathbf{P}$ as well as for the abandonment of any rival hypotheses $\mathbf{P}^{\prime}$. In Adler's own words, "to judge all-out is to satisfy the conditions for believing that" (Adler 2002b, p.61).

Two problems with respect to this argument become salient. The first one concerns the idea that in practical reasoning one's inclination to the deferred option survives being experienced in the form of "a kind of regret', whereas in theoretical reasoning this simply does not happen. This idea seems at odds with the commonly held intuition that often, in theoretical reasoning, something akin to this does happen - we sometimes experience the survival of our inclination to accept $\mathbf{P}^{\prime}$ even after the endorsement of $\mathbf{P}$ (where $\mathbf{P}$ and $\mathbf{P}^{\prime}$ are rival hypothesis) in the form of a kind of recalcitrant subtle doubt, or of a lack of certainty. It is quite likely that we all have been through situations in which a residual uncertainty remained underpinning an inference and manifested itself, for instance, in a rush for double-checking the infer- 
ence's steps, juxtaposing each one with the impression that the hypothesis put away moments ago had at some point appeared so good.

Second, non-isomorphism as framed by Adler is at least problematic. According to him, within theoretical reasoning one seeks the alternative which is true, not the one that is better than the others in the face of the total set of available data, i.e, within theoretical reasoning the only good enough alternative is the one corresponding to the truth, so that for an alternative to be accepted or believed on certain grounds has to equal to its being acknowledged as the only true one - unlike in practical reasoning, where we seek to discern between several good alternatives which one is the best. Within practical reasoning, what it is for an alternative to be taken as the one we're supposed to select is not equivalent to it being the only good one but simply one that is superior to the others in some respect. There seems to be something right about these considerations, but at the same time there is something strange and seemingly incorrect.

It seems correct to suppose that the goal of a theoretical reasoning harbors a strong connection with truth - after all, if we reason from facts and evidence and we're looking for the perpetrator of a crime, for example, we want to get to the right person, the one who actually did it, and not merely one who seems the most suspicious, or the most likely to have done it, over other suspects (for obviously the fact that one is the most suspicious among others does not suffice to justify an attribution of authorship - the real author may simply not be in the pool of acknowledged suspects, to begin with). The same holds for cases in which we want to know the cause of a disease, or solve a mathematical problem - the demand is for the truth, not simply for something that fits better than the alternatives. On the other hand, it does not seem correct to assume that all theoretical reasoning works this way: abductive inferences are inferences (that is, they are specimens of theoretical reasonings) and they work rather differently. In comparing two scientific hypotheses which one offers the best explanation for a set of phenomena, we seek to specify which one is superior; and the criterion may be the reach of explanatory power or parsimony in contexts in which it is either not appropriate or possible to determine the truth. The same holds for a myriad of situations, such as when we want to determine which product has the best cost-effective ratio within a certain market branch — the search may even end up picking up two rival candidates, instead of just one. Adler seems to equate theoretical reasoning with inquiries of a very specific kind: those that aim at reaching the amount of evidence that would suffice to establish the truth of one single hypothesis. But not only is this far from amounting to all sorts of theoretical reasonings that there are - it does not even amount to all sorts of inquiries, not to mention the fact that both theoretical reasoning and inquiries are largely subject to operational flaws.

In any case, when Adler says that theoretical reasoning "aims at what is right", 
he is establishing the "rules of the game" of this variety of reasoning, that is, he is establishing that theoretical reasoning is ruled by certain specific norms that involve not selecting one of the alternatives unless it's the right one. The illustrative analogy of the difference between practical and theoretical varieties of reasoning, then, is the difference between the rules of poker and those of rummy: "in poker the best hand wins, while in rummy only the right sequence of cards wins" (Adler 2002a, p.4). The status of those rules, however, can be interpreted in more than one way, and it is not exactly clear whether Adler is to be taken as stating

Within theoretical reasoning, one only comes to acquire a belief, say, that $\mathbf{P}$, whenever she judges all-out that there are good and sufficient reasons for the truth of $\mathbf{P}$. (Rules of the Game - I)

or

Within theoretical reasoning, one should only come to acquire a belief, say, that $\mathbf{P}$, whenever she judges all-out that there are good and sufficient reasons for the truth of P. (Rules of the Game - II)

$R G-I I$ is prescriptive: it specifies how an epistemic agent is supposed to proceed in order to reason well. $R G-I$, in turn, is descriptive: it specifies what a mental procedure must have in order to be a theoretical reasoning. If what Adler meant is $R G-I$, he must be willing to accept that any procedure that dissents from what $R G-I$ specifies is not a proper theoretical reasoning, whereas, if he meant $R G-I I$, then he must be willing to accept that such is the procedure by which theoretical reasonings must be operated to be good, so that any different procedure renders the performed reasoning flawed.

Therefore, if Adler's argument is to have the (strong) effect of blocking in principle the occurrence of an epistemic flaw analogous to practical akrasia, it must be read as meaning $R G-I$, since it is $R G-I$, but not $R G-I I$, which makes theoretical reasoning immune to the relevant flaw ( $R G-I I$ specifies the way an agent should proceed, but leaves it open the possibility that she will not so do, namely, failing). Notwithstanding, $R G-I$ sounds "overly optimistic about human rationality", as noted by Mele (1992, p.114), and therefore it is inadequate to capture the way we (ordinary human beings in general) think and proceed - in general, we are willing to consider as proper theoretical reasoning cases in which the subject forms a judgment with respect to $\mathbf{P}$, for example, $\mathbf{f} \therefore \mathbf{P}$; and acquires the belief that $\mathbf{P}$ without possessing good and sufficient reason for the truth of $\mathbf{P}$, or under circumstances where it is at least very controversial that she so possesses. This seems to be especially common regarding hasty generalizations, which are bad inductive inferences, as in the Timothy Evans case: 


\section{TIMOTHY EVANS}

In November 1948 the British police arrested and accused Timothy Evans of the murder of his wife, Beryl. Beryl was pregnant and the couple had agreed to have an illegal abortion, allegedly as a result of which Beryl had suffered complications that led to her death. Evans was stunned and, feeling guilty for agreeing to the abortion, eventually confessed having killed his wife. As a result of his confession, the police never investigated the possibility that someone else was responsible for the crime. Four years after Evans was sentenced to death and executed, the real killer was discovered: John Christie, neighbor of the Evans couple, a serial killer who had already killed and concealed the bodies of seven women, confessed having strangled Beryl on the day of the alleged abortion and then told Evans she died due to the procedure. At the time of Beryl's murder, John Christie already had criminal records, had made two other victims and concealed their bodies in his front yard - that is, if only the police had conducted an investigation at his adjoining house and found these two bodies, Evans's conviction would probably have been avoided. ${ }^{14}$

In the procedure whereby the British authorities concluded that Timothy Evans murdered Beryl (P) they reasoned from Evans' confession (f) that Evans murdered Beryl (f $\therefore$ P). Provided $R G-I$, we would have to say that the British police judged allout that Evans' confession (f) amounted to good and sufficient reason for $\mathbf{P}$. Within this demeanor, however, it does not seem that the British authorities had good and sufficient reason to take $\mathbf{P}$ as true - notably because $\mathbf{P}$ was false, as well as because the only reason they had for $\mathbf{P}$ at that time (i.e., $\mathbf{f}$ ) does not seem to be neither good nor sufficient. So if $R G-I$ were the rule of thumb for this variety of theoretical reasoning, then either $\mathbf{f} \therefore \mathbf{P}$ was not really the all-out judgment by which the British authorities came to acquire $\mathbf{P}$ at the time, or the demeanor through which they came to acquire $\mathbf{P}$ cannot really count as a theoretical reasoning. That the demeanor in question cannot count as a theoretical reasoning is highly disputable (if not a theoretical reasoning, what else could it be?). However, if $\mathbf{f} \therefore \mathbf{P}$ was not the all-out judgment whereby the British authorities came to acquire $\mathbf{P}$, then the acquisition of $\mathbf{P}$ prompts a state of dissonance which is precisely what Adler was trying to show was impossible.

On the other hand, if we suppose $R G-I I$ instead of $R G-I$, the prognosis is not much better to the effect of blocking $C 1$. In this case, it does not seem that the British authorities had good and sufficient reason to take $\mathbf{P}$ as true either - not just because $\mathbf{P}$ was false, nor because it was entirely within their power to carry on a broader investigation that would have brought about that $\mathbf{P}$ was false, but above all because to carry on a broader investigation seems to correspond precisely to what is expected from law enforcement authorities in circumstances such as this (this is what is expected from them to be law enforcement authorities, to begin with), from which 
it is reasonable to assume that these authorities had a better general intellectual judgment, or a general principle regulating their epistemic conduct, according to which conclusions such as $\mathbf{P}$ should only be drawn after broad investigations have been properly conducted, since only this sort of investigation is capable of providing good and sufficient reason for the truth of $\mathbf{P}$. Nevertheless, the conclusion that $\mathbf{P}$ was drawn (and indeed the belief that $\mathbf{P}$ was acquired) prior to such an investigation, and in the full awareness that it was being drawn on the basis of (only) f, precisely setting up, once more, the state of dissonance characteristic of $C 1 .{ }^{15}$

In short, the most Adler's argument can successfully show is that the so-called "evidential akrasia" is impossible, i.e., that it is impossible for a subject to acquire a belief $\mathbf{P}^{\prime}$ in the face of evidence that she herself deems good and sufficient for $\mathbf{P}$, where $\mathbf{P}$ and $\mathbf{P}^{\prime}$ are rival hypothesis. But it does not show that it is impossible for a subject to fail to acquire $\mathbf{P}$ in the face of evidence that she deems good and sufficient for $\mathbf{P}$, as in the Wilma case; neither that it is impossible for a subject to acquire $\mathbf{P}$ in the absence of evidence that she deems good and sufficient for $\mathbf{P}$, as in the Tim Evans case. And since cases like Wilma's and Evans' are captured by $C 1$, in order to disclaim $C 1$, one needs to show that such cases are impossible, which Adler's argument do not manage to do.

\section{Arguments against $\mathrm{C} 2$ charging $\mathrm{CB}$}

As far as we can see, one's beliefs may dissent from one's judgment as to what she is supposed to believe, since arguments against $C 1$ did not succeed in demonstrating otherwise. However, as the epistemic akrasia requirements are featured by its disclaimers, for there to be epistemic akrasia, things must be such that the beliefs in question could have not been acquired. This entails that one must have some general control over her belief acquisition (so that she can fail to exercise that control eventually, thus resulting in akrasia). In particular, if epistemic akrasia is to be the analog, in the epistemic field, of what practical akrasia is in the practical field, beliefs have to be something over which we have at least as much control as we have over actions.

The default way of interpreting $C B$ is as follows: if we have over our beliefs as much control as we have over our actions $(C B)$, and if we have direct and indirect voluntary control over our actions, then we must have the same sorts of voluntary control over our beliefs for $C B$ to be true. This idea, that beliefs fall under our voluntary control, is known as "doxastic voluntarism". Doxastic voluntarism is a subjection-to-the-will-based model of control and it is advocated by authors such as James Montmarquet (1986).

Another interpretation to $C B$ is: if we have over our beliefs as much control as we 
have over our actions $(C B)$, and if we have control over our actions as far as we form a view on the merits of each envisioned course of action, then we must have control over our beliefs by forming a view on the merits of each envisioned hypothesis. This is a judgment-based model of control, within which it is practical judgment, not the will, the means by which we exercise control over our agency. Such a model is defended by David Owens (2000, 2002).

Arguments disclaiming $C B$, then, can run two basic strategies:

To reject $C B$ by denying that the subjection-to-the-will-based model of control applies to beliefs. (strategy I)

or

To reject $C B$ by denying that the judgment-based model of control applies to beliefs. (strategy II)

Advancing either (I) or (II) with the aim of arguing that $C B$ is false (and thus that ISO can no longer be interpreted as it needs to be interpreted so that $C 2$ is met) involves showing that $C 2$ indeed depends on us having, over our beliefs, either direct and indirect voluntary control or judicative (i.e., judgment-based) control of the same type we have over our actions.

\subsection{William's classic argument}

For many philosophers who adopt the subjection-to-the-will-based model of control, it is somewhat obvious that we do not control our beliefs voluntarily in the same way we control our actions, since actions are subject to our will direct and indirectly, whereas beliefs are only subject to our will indirectly. Then, for $C B$ to hold direct doxastic voluntarism ( $D D V$ ) would have to be true. But $D D V$ is false, so that $C B$ is patently false and strategy (I) does not even have to be run - that it does succeed is somewhat self-evident. Nevertheless, Bernard Williams (1973, p.148) famously advanced an argument against $D D V$, the so-called "classic argument":

It is not a contingent fact that I cannot bring it about, just like that, that I believe something (...). Why is this? One reason is connected with the characteristic of beliefs that they aim at truth. ${ }^{16}$

If people could believe propositions based solely on their will (i.e., just by wishing), they could judge a proposition as true regardless of whether they think that proposition is in fact true. Concomitantly, people would know that they have this power - that is, they would know that it is within their power to make judgments about propositions regardless of whether they think they are true. That is to say, if $D D V$ were true, Mary could believe, for example, that John is innocent regardless of 
her judging that the proposition "John is innocent" is true. In addition, Mary would know that she could acquire such belief this way, i.e., regardless of her stance on its correspondence to reality. This, however, contradicts the very nature of doxastic acquisition and obliterates the very notion of belief - believing that $\mathbf{P}$ is taking $\mathbf{P}$ as true. ${ }^{17}$ If one believes that $\mathbf{P}$, she will be surprised, or experiment some form of estrangement, whenever she finds out that $\mathbf{P}$ is false. Were $D D V$ true, however, someone who believed that $\mathbf{P}$ would not be surprised to find out at some point that $\mathbf{P}$ is false, because the truth of $\mathbf{P}$ was not taken into account for the acquisition of $\mathbf{P}$. Thus, people would not be able to face the beliefs that they have acquired from will as proper beliefs, that is, as mental states intended to represent states of affairs in the world, or as indicators of states of affairs in the actual world. Accordingly, if Williams is right, $D D V$ is not only false but conceptually unaccountable, and due to that $C B$ is false.

The classic argument, however, is pretty at odds with the basic intuition that there is a difference between belief acquisition and belief fixation. Some authors who have noted this point include Johnston (1995, p.438), Winters (1979, p.253), and ScottKakures (1994). It seems perfectly possible for a person to acquire the belief that $\mathbf{P}$ for reasons that are entirely practical (i.e., regardless of her consideration of the truth of the proposition $\mathbf{P}$ ); and to later become aware or come to acknowledge evidence in favor of $\mathbf{P}$, and then fix $\mathbf{P}$. Consider, for example, the Helen case:

\begin{abstract}
HELEN
Helen is at the hospital's waiting room awaiting news about the emergency surgery Jonas is undergoing. Then Helen is approached by a fortune teller who tells her that the surgery is going well and that nothing bad is going to happen to Jonas. Helen is skeptical of clairvoyant skills in general and knows that the words of the fortune teller are no evidence in favor of the claim in question. Nevertheless, after listening to the fortune teller, Helen comes to believe that the surgery is going well and that nothing bad is going to happen to Jonas. Moments later, one of the surgeons enters the room and announces that the surgery is going well and that nothing bad is going to happen to Jonas. Helen finally reassures herself, for she knows that the surgeon's words are good and sufficient evidence in favor of her belief and, therefore, that it reasonable for her to hold on to the belief that the surgery is going well and that nothing bad is going to happen to Jonas.
\end{abstract}

Cases like Helen's seem possible and even unexceptional. What seems to be going on in this case is that Helen acquires the belief that $\mathbf{P}$ ("the surgery is going well and nothing bad is going to happen to Jonas") from the words of the fortune teller not because she thinks such words constitute evidence of the truth of $\mathbf{P}$ but rather because she somehow wants $\mathbf{P}$ and the fortune teller's talk somehow reflects and meets her wish. We can even treat this in terms of the fortune teller's talk having 
induced in Helen the belief that $\mathbf{P}$ insofar as it meets her wish. Thus, at this point, Helen acquires $\mathbf{P}$ regardless of her consideration on the truth of $\mathbf{P}$ and based on purely practical interests. Then $\mathbf{P}$ remains tentatively installed (i.e., not properly affixed) within her doxastic mesh, until she accesses good and sufficient evidence in its favor (viz., the surgeon's testimony). At this second moment, Helen affixes $\mathbf{P}$ (taking into account what weights in favor of its being true); and she may even acknowledge her earlier position as unreasonable, as constituting a failure in acknowledging and weighting the available evidence (or its lack thereof). At the same time, it is equally conceivable that, had the surgeon came and announced that the surgery went bad and that terrible sequels were to befall Jonas, Helen would have been surprised after all, she had been believing otherwise until then. Indeed, it is even harder to picture this scenario without her being surprised.

If cases like Helen's are possible, then it seems it is possible for a person, at one point, to acquire a P-belief regardless of her consideration of the truth of the P-proposition (which is exactly what Williams had said was conceptually impossible) and, at a latter moment, to access evidence that enable her to properly affix $\mathbf{P}$, thus rendering it a proper, full-blown, belief. And it is also possible that at this latter moment she acknowledges that $\mathbf{P}$ had been acquired through force of the will (and thus unreasonably) moments ago. ${ }^{18}$

Cases akin to Helen's were presented by Ginet (2001, pp.64-5). In one of them, the individual was road tripping miles away from home when asked by his wife about whether or not he had locked the front door. He thinks he did, but he's not quite sure. Given that the only way to access evidence that would enable him to be sure was going back home and checking it out, and given the great inconvenience of so doing, he decides to believe he did lock the front door, for entirely practical reasons: just to avoid the inconvenience and to prevent his worries from disrupting his mood during the trip. What is common among these cases is that in them people find themselves in situations in which they are (at least moderately) concerned about the truth of some proposition, about not having conclusive evidence for or against a proposition, or having ambiguous evidence; and their anxiety is alleviated when they choose to act as if the proposition were true, even in the absence of adequate evidence. It seems, at least prima facie, that in such situations we have direct voluntary control over the beliefs in question, insofar as we only believe due to (at least in part) an act of will.

One might object that in such cases what people are doing is not exercising control over belief acquisition, but over something else - cases such as Helen's and Ginet's could be cases not of the subject believing a proposition, but rather accepting it. Accordingly, one decides to provisionally take a proposition as true for some practical purpose, but (contrary to what happens when proper, full-blown, beliefs are at stake) in so doing she does not commit herself to its truth. ${ }^{19}$ Or the cases in question could be cases in which one acts as if it the proposition were true ${ }^{20}$ so that she de- 
cides to behave as if the proposition were true for some practical purpose, regardless of whether or not she effectively believes, affirms, denies, or suspends judgment.

If these objections play along, they restore the power of Williams' classic argument by establishing that cases where the acquisition of a $\mathbf{P}$-proposition is distinct from its fixation (cases such as Helen's and Ginet's) are not really cases involving belief but rather other types of attitude (acceptance and act-as-if, for instance). That is, these objections work for the purpose of strategy (I), as (I) was featured.

Interestingly, however, it does not seem to make any difference for the sake of $C 2$ whether the attitude thus involved is proper, full-blown, belief or not. This is because $C 2$ is intended to be a proposition about epistemic attitudes, and attitudes such as acceptance and act-as-if are epistemic or, at least, they're attitudes that have an epistemic dimension that doesn't make up our intellectual behavior any less than the epistemic dimension of full-blown beliefs. And this, in turn, renders such attitudes equally suitable to figure in $\mathrm{C} 2$ - these are attitudes we take regarding propositions and they involve taking stances as to something being the case or not, albeit provisionally or hypothetically. In addition, these appear to be attitudes such that, in any given situation, it was possible for them to not have been undertaken: until the surgeon's showing up, Helen could have kept her judgment suspended, for example, about whether or not Jonas's surgery was going well (that is, she could have doubted the fortune teller's talk); and the character in Ginet's story could have decided to go back and check the front door. If epistemic attitudes such as these are likely to be undertaken by a subject in contexts where so doing contravenes the recommendation of her better judgment, it seems that the conditions for epistemic akrasia are met - even because episodes of practical akrasia also seem possible to occur involving practical attitudes that fall short of "proper actions" (or "full-blown actions"), such as dispositions to act, choices or decisions, for example, provided these attitudes satisfy CTRL.

In other words, Williams' classic argument works for the effect of blocking $C 2$ only if $C 2$ is built up the way its disclaimers build it up: in a way that requires or stipulates that the epistemic attitude in question is proper, full-blown, belief. Then, William's classic argument against $C B$ will have succeeded in demonstrating that epistemic akrasia is not possible (namely, because $C 2$ will have failed to be satisfied) - but only if they are right in that this is the only correct way of framing $C 2$ for the purpose of assessing whether or not epistemic akrasia is possible.

\subsection{Owens' alternative argument}

When two possibilities of action concur, the agent must form a view as to which of the two is best all things considered, i.e, she must form an all-things-considered judgment. Nevertheless, this judgment still allows for the dismissed alternatives to 
retain some of their value: although I think the best thing to do at this point is to not eat another chocolate, provided that I want to avoid an indigestion at the end of the day (all-things-considered judgment), the idea of eating one more chocolate now still retains some of its appeal, as it would be quite agreeable to eat one more chocolate now from the point of view of my immediate pleasure (all-out judgment). Practical akrasia is possible precisely because I can act motivated by this latter judgment rather than the former.

David Owens takes judgment-formation as a means for the agent to exercise control over her actions: she can do what she judges best, or she can do something else. The first possibility represents the full exercise of the agent's control - she proceeds so that her action is in full agreement with what she deems best all-things-considered. The second possibility, in turn, represents a loss of control: the agent fails to proceed so that her action is in agreement with her all-things-considered judgment.

As Owens points out, this judgment-based model of control applies to actions due to the fact that actions are intentional, that is, goal-directed; and because actions serve a variety of purposes, that is, a myriad of actions serve several aims: eating one more chocolate now is oriented towards immediate pleasure, whereas refraining to so do is oriented towards ensuring an indigestion-free near future. In the end, choosing between these two possibilities of action is a matter of choosing between their two respective aims, or outcomes. Thus, for this model of control to apply to beliefs, beliefs must attend the two alluded requirements: they must be goal-oriented; and they must serve a variety of aims.

That beliefs are goal-oriented is something we can accept stilly - in fact it seems that beliefs are oriented towards the goal of being acquired only if they get things right, that is, only if they are true (Owens 2002, pp.390-2). While this is actually pretty debatable, it seems acceptable, once it explains, for instance, why we simply cannot believe something for which we have no evidence just because someone offered us a large sum of money. Now, that beliefs serve a variety of purposes, according to Owens, is more difficult to accept: it seems that beliefs serve the sole purpose of corresponding to reality, that is, of representing the world, so as to allow us to navigate it. And if this is so, then beliefs do not meet the minimum requirements that would allow for the judgment-based model of control to apply to them (thus leading strategy (II) to succeed and rendering $C B$ false).

One might confront Owens' considerations with the Zoologist case:

\section{ZOOLOGIST}

A zoologist goes into a research endeavor aimed at learning about the behavior of certain species of wolf that is believed to inhabit certain territory. Resources are distributed and schedule is planned, as for the goal of the research, which is to cover the largest lot of territory as possible and to attain as many observations as possible, within the available (limited) amount of time. 


\begin{abstract}
Knowing that wolves are nocturnal and that the territory inhabited is pretty large, the zoologist demarcates numerous spots within the terrain map, and arranges facilities so as to spend his nights awaken, in order to maximize the probability of success in observation. While spending the night in each spot, the zoologist must lurk and seek to behold wolves. If no wolf shows up, he must decide whether the best move is to spend one more night within the same spot or to move into the next one. Staying for too many nights in the same spot may result in the zoologist running out of time and delaying the research schedule, thus preventing him from sweeping a large area. Moving to the next spot too quickly, however, may also undermine the research efforts, for he might end up having covered all the demarcated spots but without accomplishing a fair amount of observations.
\end{abstract}

After spending one night in one spot without having beholden a wolf, the decision as to stay or move is driven out of a process within which the zoologist reasons as follows: if he believes that the chances of beholding a wolf next night in his current spot are high (if he has heard howls during the night, for example), then he must stay. If, on the contrary, he believes that his current spot is not very promising for next night, then he'd better move. At a certain time, he might believe that his current spot is promising, so that he should indeed spend one more night there, while, at the same time, judging that, given the amount of time left, it is moving - not staying - that would increase the success of the investigation the most (by increasing his chance of being able to sweep the larger area). Conversely, it may happen that the zoologist judges that, given the amount of time left, he should spend one more night at his current spot, albeit believing that the current spot is not a very promising one (if, for instance, no howls have been heard). In both cases, following Owens's, the beliefs at stake are goal-directed (they aim at being acquired only if true). However, contrary to Owens' considerations, these beliefs appear to serve a double purpose namely, getting it right about the current spot (or each of the spots) being promising or not and getting it right about the best way of managing time so as to ensure the highest chance of succeeding in the research endeavor. Consequently, these beliefs seem pretty eligible to be subject to the judgment-based model of control, thus configuring what Owens said was impossible.

Owens, however, could object to this by claiming that the attitude undertaken by the Zoologist so as to prompt a decision as to stay or move is not proper believing, but rather guessing. Like believing, guessing aims at the truth; but the two attitudes are not purposive "in the same way" (Owens 2002, p.392). In making an individual guess (a guess as to whether the current spot is promising or not), the Zoologist is trying to get that particular matter right. However, the correctness of this particular guess is not the only goal he is pursuing - his judgments about when to move, about how many hours he ought to wait before setting a resolution, etc., will be informed by his need to make the best of the research endeavor (that is, by attaining as many observations 
as he possibly could as well as by covering as many spots as possible throughout the terrain). ${ }^{21}$ Guessing-situations, according to Owens, are rich in akratic possibility precisely because the attitude involved, guessing, unlike believing, falls under the judgment-based model of control (since it satisfies both the requirements for this model of control). Then akrasia of guessing is possible, following Owens, but not intellectual or epistemic akrasia (qua full-blown belief akrasia).

It is not clear, however, why attitudes such as the Zoologist's, once falling under the judgment-based model of control, cannot figure in an intellectual or epistemic akrasia description - after all, the Zoologist's endeavor is an intellectual, or epistemic one; and the attitudes undertaken by him as part of this endeavor (even if they indeed fall short of proper full-blown belief) are epistemic, or, at least, have an evident epistemic dimension. Like in the Helen and the Ginet cases, the epistemic dimension underpinning the attitude in question doesn't make up the Zoologist intellectual behavior any less than the epistemic dimension of full-blown beliefs. So, again (as in the cases involving acceptance and act-as-if attitudes), the only apparent reason why guessing attitudes are not suitable to figure in $C 2$ is because $C 2$ was written in a way that precludes it - as we saw, the way $C 2$ is casted by the epistemic akrasia disclaimers it requires or stipulates that the attitude involved in an hypothetical epistemic akrasia episode is belief, that is, full-blown belief. Notwithstanding, one could wonder whether this really is the only correct way to frame epistemic akrasia.

\section{Final Remarks}

While Pettit and Smith's and Adler's arguments give out, Williams' and Owens' succeeded in purporting that full-blown belief akrasia is not possible, once one of its conditions - namely, $\mathrm{C} 2$ - isn't met. While this may be true of full-blown beliefs, however, it doesn't seem to be true of the full range of epistemic, or intellectual, attitudes that make up our epistemic agency. Actually, the very fact that $C 2$ is not met appears to have came about only because $C 2$ was featured in a way that already paved the way for it to not be met: by restricting the epistemic attitudes at stake in the akrasia episode to full-blown belief. It seems perfectly possible, however, for $C 2$, as well for $C 1$, to be featured in alternative, broader, ways. Compare their default featuring with these alternative ones:

The epistemic attitude involved in an epistemic akrasia episode is acknowledged by the individual herself as dissenting from her better epistemic judgment as to what attitude would be appropriate. $\left(C 1^{\prime}\right)$

Things are such that it was possible for the epistemic attitude involved in the epistemic akrasia episode to not have been undertaken. ( $\left.C 2^{\prime}\right)$ 
In $C 1^{\prime}$ as well as in $C 2^{\prime}$ the ideas of full-blown belief and full-blown belief acquisition were replaced by the broader notions of epistemic attitude and epistemic attitude undertaking, respectively, in comparison to the default formulations; and neither $C 1^{\prime}$ or $C 2^{\prime}$ undermine ISO. These seem to be legitimate ways of framing the akrasia requirements for the epistemic variety, mainly because full-blown belief is not the only element in our intellectual or epistemic lives' landscape (though it is likely the most notable one): attitudes such as guessing, questioning, presupposing, inferring, being curious about, being skeptical about, doubting, assuring, considering, comparing, supposing, accepting, inquiring, deliberating, etc. also figure in our theoretical reasonings and also inform our epistemic agency (though not always in the more appropriate or more virtuous ways). Then we have no reason to think that intellectual "misbehaviors" involving undertaking these attitudes in circumstances in which one's better judgment tells otherwise do not qualify as mild forms of epistemic akrasia (as something that is, for theoretical reason, pretty analogous or isomorphic to what practical akrasia is for practical reason).

\section{References}

Adler, J. 2002a. Akratic Believing? Philosophical Studies 110: 1-27.

Adler, J. 2002b. Belief's Own Ethics. Cambridge: The MIT Press.

Alston, W. 1989. The Deontological Conception of Epistemic Justification. In: Essays in the Theory of Knowledge, pp.115-52. Ithaca: Cornell UP.

Bratman, M. 1992. Practical Reason and Acceptance in a Context. In: Faces of Intention, pp.15-34. Cambridge: Cambridge University Press.

Buckareff, A. 2004. Acceptance and Deciding to Believe. Journal of Philosophical Research 29: 173-90.

Christensen, D. 2010. Rational Reflection. Philosophical Perspectives 24: 121-40.

Cohen, J. 1989. Belief and Acceptance. Mind 98: 367-89.

Cohen, J. 1992. An Essay on Belief and Acceptance. Oxford: Oxford University Press.

Coates, A. 2012. Rational Epistemic Akrasia. American Philosophical Quarterly 49: 113-24.

Davidson, D. 1970. Events and Particulars. Noûs 4: 25-32.

Davidson, D. 1980. How Is Weakness of the Will Possible? In: Essays on Actions and Events, pp.21-42. Oxford: Clarendon Press.

Davidson, D. 1986. A Coherence Theory of Truth and Knowledge. In: E. LePore (ed.) Truth and Interpretation, pp.307-19. Oxford: Blackwell's.

Davidson, D. 1999. The Emergence of Thought. Animal Mind 51: 7-17.

Dretske, F. 1971. Reasons, Knowledge and Probability. Philosophy of Science 38: 216-20.

Engel, P. 1998. Believing, accepting, and holding true. Philosophical Explorations I(2): 14051.

Engel, P. 1999. Dispositional belief, assent, and acceptance. Dialectica 53(3-4): 211-26.

Engel, P. 2012. Trust and the Doxastic Family. Philos Stud 161: 17-26. 
Ginet, C. 2001. Deciding to Believe. In: M. Steup (ed.) Knowledge, Truth, and Duty, pp.63-76. Oxford: Oxford University Press.

Hare, R. 1952. The Language of Morals. Oxford Clarendon Press.

Harman, G. 1980. Reasoning and Evidence One Does Not Possess. Midwest Studies in Philosophy 5: 165-82.

Heil, J. 1983. Doxastic Agency. Philosophical Studies 43: 355-64.

Hookway, C. 2001. Epistemic Akrasia and Epistemic Virtue. In: A. Fairweather; L. Zagzebski (eds.) Virtue Epistemology: Essays on Epistemic Virtue and Responsibility, pp.178-99. Oxford: Oxford University Press.

Hurley, S. 1989. Natural Reasons: Personality and Polity. New York: Oxford University Press.

Johnston, M. 1995. Self-Deception and the Nature of Mind. In: C. MacDonald; G. MacDonald (eds.) Philosophy of Psychology. Cambridge, Mass.: Blackwell.

Kampa, S. 2019. Obsessive-Compulsive Akrasia. Mind \& Language 1: 1-18.

Klein, P. 1981. Certainty: A Refutation of Skepticism. Minneapolis: University of Minnesota Press.

Lasonen-Aarnio, M. 2014. Higher-order evidence and the limits of defeat. Philosophy and Phenomenological Research 88(2): 314-45.

Mele, A. 1986. Incontinent Believing. The Philosophical Quarterly 36: 212-22.

Mele, A. 1992. Acting for Reasons and Acting Intentionaly. Pacific Philosophical Quarterly 73: 355-74.

Montmarquet, J. 1987. Epistemic Virtue. Mind 96: 482-97.

Owens, D. 2000. Reason without Freedom. London: Routledge.

Owens, D. 2002. Epistemic Akrasia. The Monist 85: 381-97.

Owens, D. 2003. Does Belief Have An Aim? Philosophical Studies 115: 275-97.

Pettit, P; Smith, M. 1996. Freedom in Belief and Desire. Journal of Philosophy 93: 429-49.

Raz, J. 2007. Reasons: Explanatory and Normative. Oxford Legal Studies 1: 1-25.

Ribeiro, B. 2011. Epistemic Akrasia. International Journal for the Study of Skepticism 1: 18-25.

Rorty, A. 1981. Essays on Aristotle's Ethics. University of California Press.

Rorty, A. 1983. Akratic Believers. American Philosophical Quarterly 20: 175-83.

Schwitzgebel, E. 2001. In between believing. Philosophical Quarterly 51: 76-82.

Shah, N. 2003. How Truth Governs Belief. Philosophical Review 112: 447-82.

Shah, N.; Velleman, D. 2005. Doxastic deliberation. Philosophical Review 114: 497-534.

de Sousa, R. 1987. The Rationality of Emotion. MIT Press.

Steup, M. 2000. Doxastic Voluntarism and Epistemic Deontology. Acta Analytica 15: 25-56.

Vahid, H. 2006. Aiming at Truth: Doxastic vs. Epistemic Goals. Philosophical Studies 131: 303-35.

Velleman, J. 2000. On the Aim of Belief. In: The Possibility of Practical Reason. Oxford University Press.

Weatherson, B. 2008. Deontology and Descartes' Demon. Journal of Philosophy 105: 540-69.

Wedgwood, R. 2012. Justified Inference. Synthese 189: 273-95.

Whiting, D. 2012. Does Belief Aim (Only) at the Truth? Pacific Philosophical Quarterly 93 : 279-300.

Wiggins, D. 1987. A Sensible Subjectivism. Oxford: Oxford University Press.

Williams, B. 1970. Deciding to Believe. In: H. E. Kiefer; Milton K. Munitz (eds.) Language, Belief, and Metaphysics, pp.95-111. Albany: Suny Press. 
Williams, B. 1973. Ethical Consistency. In: Problems of the Self. Cambridge: Cambridge University Press.

Williams, S. 1990. Belief, Desire and the Praxis of Reasoning. Proceedings of the Aristotelian Society XC: $119-42$.

Williamson, T. 2011. Improbable Knowing. In: T. Dougherty (ed.) Evidentialism and its Discontents. Oxford University Press.

Williamson, T. 2014. Very Improbable Knowing. Erkenntnis 79: 971-99.

Winters, B. 1979. Believing at Will. Journal of Philosophy 76: 243-56.

Woffinden B. 1988. Miscarriages of Justice. London: Hodder \& Stoughton.

Zalabardo, J. 2010. Why believe the truth? Shah and Velleman on the aim of belief. Philosophical Explorations 13: 1-21.

\section{Notes}

${ }^{1} \mathrm{~A}$ neighboring debate that has been going on more recently under the same heading is the one whose central issue is the question of whether epistemic forms of akrasia could be rational (qua normatively positive), which is actually a debate on level-splitting. Though these two debates are deeply interconnected (in that for something to be rational or irrational it has to be, first, possible), getting into the latter is beyond the scope of this paper. For more on this, see Weatherson (2008), Christensen (2010), Coates (2012), Wedgewood (2012), Lasonen-Aarnio (2014) and Williamson (2011, 2014).

${ }^{2}$ The Greek word "akrasia", whose literal translation is "lack of self-control", began, in the midst of the twentieth century, to be used as a general term to refer to the phenomenon commonly talked about as "weakness of the will" or "incontinence" - one's inclination to act against her own better judgment, or the failure of her better judgment to motivate her to act accordingly. A simplified technical way of characterizing it is provided by Kampa (2019, p.3): for any subject $S$ and action $\phi, S$ incurs in practical akrasia with respect to $\phi$ in case (i) $S$ does $\phi$, although currently believing that all of her practical reasons support non- $\phi$, or (ii) $S$ refrains from $\phi$ ing, although currently believing that all of her practical reasons support $\phi$; and (iii) $S$ has control over whether or not to $\phi$. As highlighted by Hookway (2001), the many ways practical akrasia is featured by philosophers are surprisingly varied. Some describe the akratic subject as the subject who performs one action while acknowledging that there is a better reason to perform another; others describe him as the subject who performs an action despite acknowledging that the reason for performing it is inappropriate. Some identify the focus of akrasia as a choice that is at odds with one's judgment (Wiggins 1987, p.240), others as an action (de Sousa 1987, p.199; Rorty 1981, p.175, Davidson 1970, pp.21-2); and others as an intention (Williams 1990, p.120); where these different characterizations need not be inconsistent.

${ }^{3}$ Although Aristotle denies that it is indeed possible for the subject we typically refer to as akratic to act intentionally, voluntarily and in full knowledge of what he is doing.

${ }^{4}$ By this I mean simply that the judgment condition and the control condition are viewed by many as the two necessary conditions that an episode has to meet in order to be correctly described as an instance of practical akrasia; and together they yield the sufficient condition for the phenomenon. 
${ }^{5}$ These authors include Pettit and Smith (1996), Adler (2002a), Hurley (1989), Owens (2002) and Raz (2007). Their position is in direct contrast with the one held by authors such as in Rorty (1983), Heil (1984), Mele (1986) and Ribeiro (2011), to whom the phenomenon is not only possible but also pervasive in our lives.

${ }^{6}$ To be sure, two outcomes are possible: either the arguments intending to show that $C 1$ and $C 2$ cannot be simultaneously met without this conflicting with the standard interpretation of ISO fail, in which case we are to conclude that it has not been demonstrated that epistemic akrasia (as it has been characterized) is impossible; or these arguments succeed, and $C 1$ or $C 2$ or both can only be met if we let go of $I S O$, in which case we are to conclude that there is no such thing as an epistemic akrasia, at least not as it has been characterized, and that the concrete cases that were once enrolled as instances of the phenomenon are actually cases of other sorts of epistemic (mis)behavior that are yet to be accounted for. No ultimate argument can prove that the epistemic akrasia disclaimers are wrong, for no argument can definitely establish that epistemic akrasia is possible. On the other hand, if the strongest arguments purporting that it is not possible are refuted, then we get strong reason to think that the epistemic akrasia disclaimers are wrong and that the phenomenon is actual. This, in turn, opens room for further discussions on whether particular instances of epistemic akrasia could be normatively positive.

${ }^{7}$ I'll alternate freely between the locutions "epistemic", "doxastic", "intellectual" and "theoretical". Though I acknowledge that these expressions can be given completely distinct senses, choosing among them for the purpose of this paper is more of a matter of stipulation than of technical precision.

${ }^{8}$ By saying that this process must be infallible in order for Pettit and Smith's argument to work I'm not evoking the notion of epistemic fallibility, which is basically the fact that we can believe justifiably (i.e., rationally) and yet falsely. What I mean here is simply that for Pettit and Smith to succeed in their intent of showing that theoretical reason is not prone to configure the state of affairs characteristic of $C 1$ the process by means of which one's better theoretical or epistemic judgment regarding a certain matter results in the incorporation of a belief on that particular matter into the agent's doxastic mesh needed to be immune to failure, for otherwise (if this process, for whatever reason, does not translate into the acquisition of the belief in question) the agent will end up precisely in the state of affairs characteristic of $C 1$ in case she has a precedent belief on that very matter.

${ }^{9}$ Adler raised the point that cases such as Wilma's merely appear to be, but are not, cases of epistemic akrasia because the consideration that lead the agent into the acquisition of the belief that is at odds with evidence is not included in the evaluative basis of judgment, that is, it is not an epistemic reason. "Any normal [believer] agent," says Adler, "needs to recognize, and be competent to apply, a distinction between epistemic and non-epistemic reasons, since non-epistemic reasons are constantly present for many of our beliefs. Its pull must therefore be regularly resisted (...)" (Adler 2002a, p.12). Thus, Adler believes that someone like Wilma is merely behaving as a non-normal epistemic agent, but not incurring in epistemic akrasia. However - this point seems to have slipped Adler's mind - it is not one of the requirements for epistemic akrasia that the belief contrary to one's better epistemic judgment be acquired only from epistemic reasons; just as it is not one of the requirements for practical akrasia that the action contrary to one's better practical judgment be undertaken only from reasons that are non-epistemic. Prima facie, any belief that one has or holds that dissents from what she 
takes to be what she should believe is eligible to frame the situation as an epistemic akrasia episode, as well as any action that one takes which dissents from what she takes as what she should do suffices to frame the situation as a practical akrasia episode.

${ }^{10}$ This would be a "detached judgment", or an "all-out judgement", in Davidson's terminology (1986, 1999). A detached judgment is a judgment "detached from its all-thingsconsidered evaluative grounding", cf. Adler 2002a, p.3.

${ }^{11}$ A somewhat similar idea is presented by Hurley (1989), who argues that whenever there's epistemic conflict between reasons to believe - for instance, when we access evidence e favoring not-p and evidence $\mathbf{f}$ favoring $\mathbf{p}$, we find out whether $\mathbf{p}$ is more likely than not-p all-things-considered by figuring out what is more likely relatively to the conjunction e \& f. If, by means of this demeanor, we find out that $\mathbf{p}$ is more likely than not-p, there is no remaining reason to believe not-p, even if not-p is more likely than $\mathbf{p}$ relatively to e (contrary to what goes on within practical conflict). This argument is endorsed by Raz (2007, p.6) to the effect of denying the very possibility of epistemic akrasia. Other authors that see the matter similarly include Dretske (1971), Harman (1980) and Owens (2000).

${ }^{12}$ Adler himself does not develop the idea of "defeater", limiting himself to highlighting that it amounts to "an intuitive and unavoidable notion" (Adler 2002b, p.328). He mentions, as a reference, the work of Klein (1981).

13“The fundamental disanalogy is that the goal of theoretical reasoning is all-out or full belief, and so the (threshold) acceptance of a proposition. When theoretical reasoning reaches that goal, contrary or undermining evidence is nullified. So there is no evidence to play the role of conflicting desires in drawing the agent away from his better judgment". Cf. Adler 2002a, p.18.

${ }^{14}$ Adapted from Woffinden (1988).

${ }^{15}$ Of course, the Tim Evans case can be interpreted as a case of hypocrisy or malice on behalf of the law enforcement authorities. There is no doubt that this happens and that, in it, the final situation does not configure $C 1$. However, unless one can give reasons why the case should be interpreted as a case of pure and simple evil, there is no reason to think that it cannot be read as a bona fide case of flaw.

${ }^{16}$ This argument was also presented in Williams (1970).

${ }^{17}$ In fact this idea - "to believe that $p$ is to believe that $p$ is true" - is not the only possible way of interpreting Williams' passage where he says that it is necessarily (and not as a matter of contingency) that "beliefs aim at the truth". Aiming at the truth is something that can be understood in more than one way, and there is a whole separate discussion devoted to understanding what these ways are and which of them would be the proper one. See, for example, Velleman (2000), Owens (2003), Shah (2003), Shah and Velleman (2005), Vahid (2006), Zalabardo (2010) and Whiting (2012). For present purposes, however, I'll refrain from getting into this discussion by assuming, without committing myself to any particular view, that what Williams means (and what the central intuition of authors who, like him, deem DDV false) is that there is a nexus between believing and taking as true; a nexus that, of whatever kind, makes it impossible for a subject to believe that $p$ without judging that $p$ is true.

${ }^{18}$ I do not wish to commit myself here to any particular taxonomy of the doxastic family, for I take it to be sufficient, for present purposes, to commit myself to the idea that there is a variety of forms of assent, among which belief is only one species. This idea reaches back at 
least to the stoics and has been contemporarily defended by authors such as Cohen (1989, 1992), Bratman (1992), Engel (1998, 1999) and Schwitzgebel (2001). For a nice review on this, see Engel (2012). The idea that there is a variety of mental states that share with paradigmatic beliefs some features, but lack others calls for a distinction between full belief, or full-blown belief, and other belief-like attitudes, that deserve the title of "belief" only by courtesy. I also do not want to advance any technical definition of full-blown belief here. For present purposes, it suffices that I state, in very broad terms, that a full belief or full-blown belief differs from other belief-like attitudes in that the former is evidence-responsive in a way that the later are not.

${ }^{19}$ See, for instance, Buckareff (2004), Bratman (1999) and Cohen $(1989,1992)$.

${ }^{20}$ See, for instance, Alston (1989, pp.122-7) and Steup (2000).

${ }^{21}$ Owens presented a somehow akin case: the case of an individual who is going through a pop quiz by guessing answers. See Owens 2002, p.392.

\section{Acknowledgments}

This work was supported by the Coordinating Agency for Advanced Training of Graduate Personnel (CAPES). A previous version of this paper has been presented at the seminars of the research group in Logics, Science, Mind and Language held at Federal University of Minas Gerais. I would like to thank all my colleagues and others partakers who attended these seminars for their helpful comments. I am especially grateful to professors André Abath and Ernesto Perini for their insightful remarks and suggestions. I'm also thankful for two anonymous referees of Principia, whose comments helped me to improve this paper. 